Original Research Paper

\title{
Plane Versus Elastic Wave AVO Anisotropic Synthetic Modeling in Derby Field, Southeastern Niger Delta
}

\author{
Chukwuemeka Ngozi Ehirim and Nnamdi Ogbonna Chikezie \\ Department of Physics, Geophysics Research Group, \\ University of Port Harcourt, P.O. Box 122, Choba, Port Harcourt, Nigeria
}

\author{
Article history \\ Received: 06-11-2016 \\ Revised: 20-04-2017 \\ Accepted: 04-05-2017 \\ Corresponding author: \\ Chukwuemeka Ngozi Ehirim \\ Department of Physics, \\ Geophysics Research Group, \\ University of Port Harcourt, \\ P.O.Box 122, Choba, Port \\ Harcourt, Nigeria \\ Email: ehirimen@yahoo.com
}

\begin{abstract}
AVO based Zoeppritz's plane wave and elastic spherical wave anisotropic synthetic modelling have been investigated in Derby field, Southeastern Niger delta. The objective of the study is to investigate the influence of anisotropy on plane and elastic wave AVO synthetics modeling over shale-gas sand horizons in the field. Well log data was check shot corrected and correlated with pre-stack data and a zero phase wavelet was extracted after well conditioning and petro physical analysis. Elastic and plane wave algorithms were then used to generate offset-dependent anisotropic synthetic seismograms respectively, using p-wave sonic, s-wave and density logs and Thompsen's epsilon $(\varepsilon)$ and delta $(\sigma)$ anisotropic logs for a transversely isotropic media. Results revealed that seismic anisotropy for AVO based analysis is better modelled with elastic rather than the conventional Zoeppritz's plane wave model and their approximations for transversely isotropic media at larger offsets. This is attributed to the breakdown of the Zoeppritz's plane wave model and their linearized approximations at large offsets or near the critical critical angle. Using elastic synthetic model for anisotropic AVO analysis will not only ensure that the reservoir will be adequately imaged, but misinterpretation of data and misplacement of the well will be circumvented.
\end{abstract}

Keywords: Elastic Wave Model, Zoeppritz's Plane Wave Model, Seismic Anisotropy and AVO

\section{Introduction}

Seismic synthetic modelling is the key to obtaining a better fit with the real seismic data. It forms the basis for understanding the seismic signature especially, in anisotropic AVO analysis of pre-stack seismic data for lithology prediction and direct hydrocarbon indication (Castagna, 2001). These reservoir variables are mainly extracted at mid-to-far offsets were anisotropy of rock formations becomes significant. Studies show that the effect of anisotropy increases with offset up to the critical angle where most of the seismic information lies (Ruger, 1997).

Anisotropy is the variation in physical properties especially, velocity of rock formations with direction (Zhijing, 2002). Though presumably weak, it has a strong influence on the seismic data. Anisotropy decreases the amplitude of reflection coefficients of $p$ waves with increasing offset (Williams and Jenner, 2002). This is largely due to the effect on the shape of the incident wave front which determines the magnitude of the incident angle. The shape of the p-wave incident wave front is determined by two principal anisotropic parameters: Epsilon $(\varepsilon)$ and delta $(\sigma)$ in the overburden. $\varepsilon$ is the p-wave anisotropy and $\sigma$ is a nonintutive amalgamation of constants of elasticity that controls the form of the attenuation at intermediate angles that affects logging responses and AVO directly (Thomsen, 1996).

It is therefore, evident that wave propagation effects can significantly affect Amplitude Variation with Offset (AVO) measurements in an anisotropic medium and as such, if the proper radiation pattern (plane or spherical wave propagation) is not taken into account during AVO anisotropic modelling, computed AVO attributes may differ significantly from the correct quantities (Castagna, 2001). Two most commonly used anisotropic AVO modelling approaches are the Zoeppritz's plane wave and Elastic spherical wave methods.

However, due to the complexity of the Zoeppritz's equations, linearized weak-contrast, small angle and weak anisotropy approximations has become a routine anisotropic AVO modelling tool for reservoir 
characterization (Tsvankin et al., 2010). This linearized plane wave single layer assumption has its short comings as it does not model the reality where a spherical wave is incident on a group of layers in contrast to the Elastic Wave Algorithm which model all components simultaneously. This will undoubtedly, impact on the AVO responses of both methods especially, at far offsets when used in anisotropic synthetic modelling for AVO analysis.

Plane wave and Spherical wave AVO anisotropic synthetic modelling for weak anisotropy and Vertically Traverse Isotropic (VTI) media have been studied by several authors (Rüger, 1997; 1998; Thomsen, 2002; Veeken and Da Silva, 2004), using linearized plane wave approximations to Zoeppritz's equation and elastic spherical wave method, respectively. The authors reported in their studies that anisotropy produces noticeable and significant AVO effects as a function of the degree of anisotropy with increasing incident angle (offset) for both methods. Li (2003), studied plane wave versus spherical wave anisotropic AVO synthetic modelling for a two-layer gas reservoir sand and reported that the models agree well on isotropy but show opposite AVO effect in anisotropy. The author concluded that the effect is greater for plane than spherical wave model.

Most hydrocarbon reservoirs in Niger delta and the overlying medium are often anisotropic (Ogagarue et al., 2010) and anisotropic synthetic modelling has routinely been carried out using linearized approximations to true Zoeppritz's plane wave reflection coefficients for AVO analysis. The purpose of this present study therefore, is to model anisotropic offset dependent reflectivity using Zoeppritz's plane wave and elastic spherical wave modelling approaches and compare the results to deduce the effect of anisotropy on the AVO responses of both methods and suggest the most robust approach for anisotropic based AVO analysis in Derby field (Fig. 1).

\section{Geology of the Study Area}

The Niger Delta ranges from Paleocene to present in geological age. Gas and Oil have been established in the reservoir rocks ranging from Oligocene to Miocene. The delta has a tripartite lithostrgraphic succession in which a regressive sequence is properly defined (Fig. 2). The delta sequence is mainly a sequence of over pressurized marine clays called Akata formation that is mainly composed of marine shales which forms the major source rocks for hydrocarbon. It is estimated that the formation is up to 7,000 m thick (Doust and Omatsola, 1990).

The overlying Agbada Formation consists of paralic silicic clastics over 3,700 $\mathrm{m}$ thick. This is the actual deltaic portion of the sequence with a lower section comprising of shale and sandstone beds deposited in equal proportions and an upper portion which is mostly sandy, with only minor shale intercalations. The sands are mainly unconsolidated reservoir sands while the shales function as cap rocks. Majority of hydrocarbon discovered and produced so far in the Niger Delta basin till date have been reservoired in the Agbada formation (Ejedawe, 1981; Evamy et al., 1978; Doust and Omatsola, 1990). These two formations were finally capped by continental gravels and sands called Benin formation. This consists of alluvial and upper coastal plain sands deposits about 2,000 m thick (Avbovbo, 1978).

\section{Method of Study}

The dataset used for this study is a full 3D pre-stack p-wave seismic data processed into CDP super gathers (Fig. 3.) and Derby well 1 in the field consisting of compressional or sonic log, gamma ray log, density log, true formation resistivity log, calliper logs and check shot data. Hampson Russell (HR) software was used to perform all the analyses and comparisons that were required for this study.

Since well log data is the basic input required to create offset dependent synthetics, it therefore follows that $\log$ correction and Quality Control (QC) are necessary requirements to produce good results. Well data was corrected for shale washout effects and despiked using median filter to remove high frequency noise and other borehole irregularities. Well log analysis was performed and three prospective reservoirs zones HDI, HDII and HDIII were delineated (Fig. 4).

S-wave log was created using Castagna's mud rock relationship and modeled to the correct S-wave behaviour for gas sand by fluid substitution after rock physics analysis. Thomsen's anisotropy well logs epsilon $(\varepsilon)$ and delta $(\sigma)$ were created using the empirical relationship presented by Li (2002) from gamma ray $\log$ (Fig. 5).

The well data was check shot corrected and correlated with the pre-stack data and a zero phase wavelet was extracted. The correlation between the $\log$ and pre-stack data is an important QC step to enable us compare synthetic models with the CDP gather around the well location. Zoeppritz's plane wave and elastic spherical wave algorithms were then used to generate offset-dependent anisotropic synthetic seismograms respectively, for shale-gas sand interfaces using p-wave sonic, s-wave and density $\operatorname{logs}$ and the Thompsen's epsilon and delta anisotropic $\log$ for a transversely isotropic media. The result of both algorithms were subsequently, compared with the real CDP gather for anisotropic AVO modeling in Derby field. 


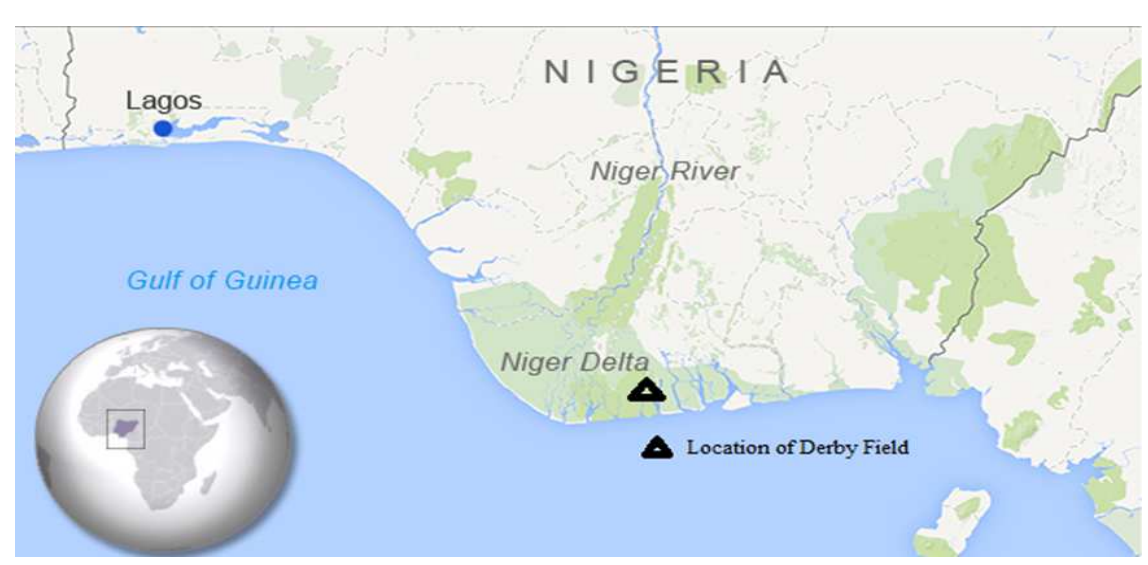

Fig. 1. Location map of the study area

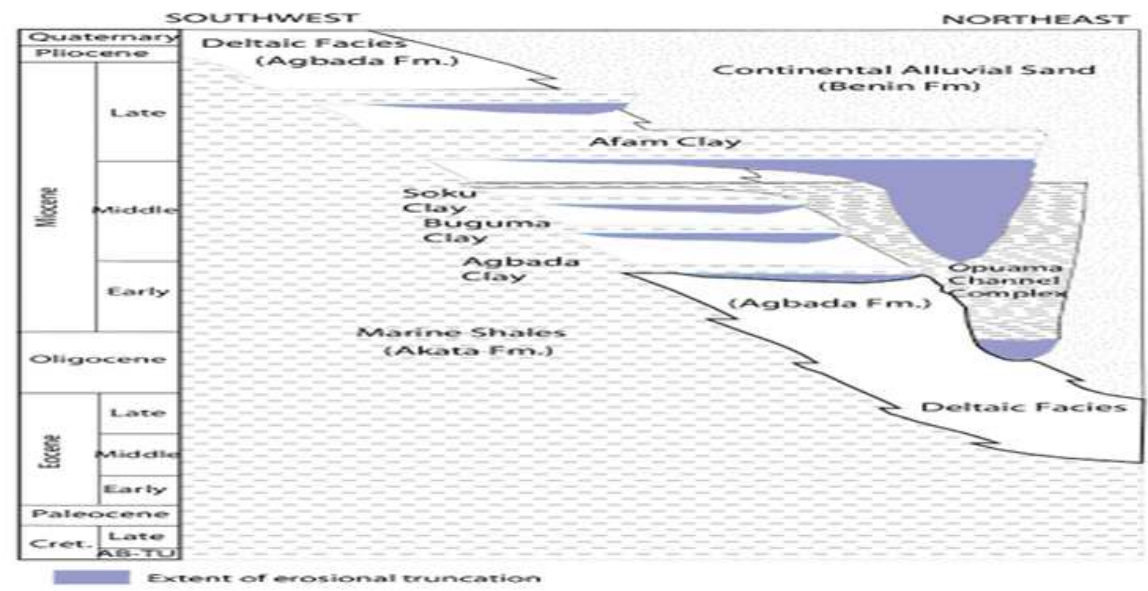

Fig. 2. Stratigraphic succession map of the Niger delta

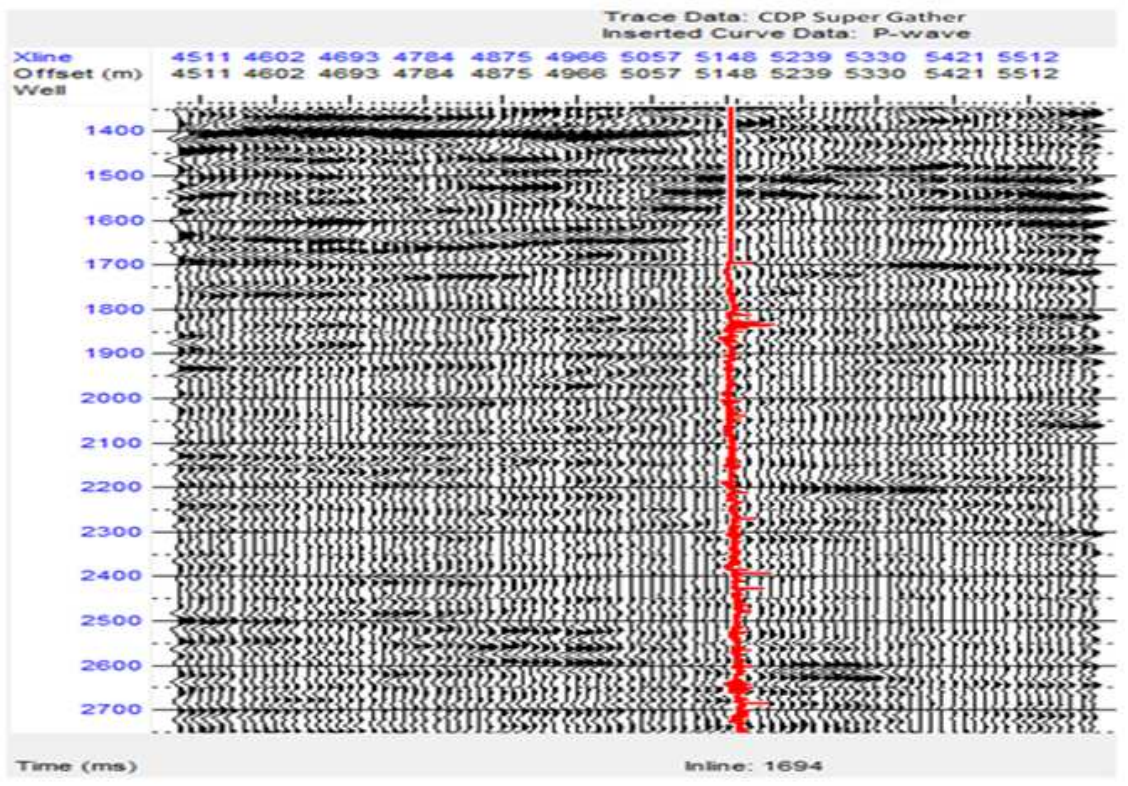

Fig. 3. 3D processed CDP super gather and inserted p-wave of the study area 


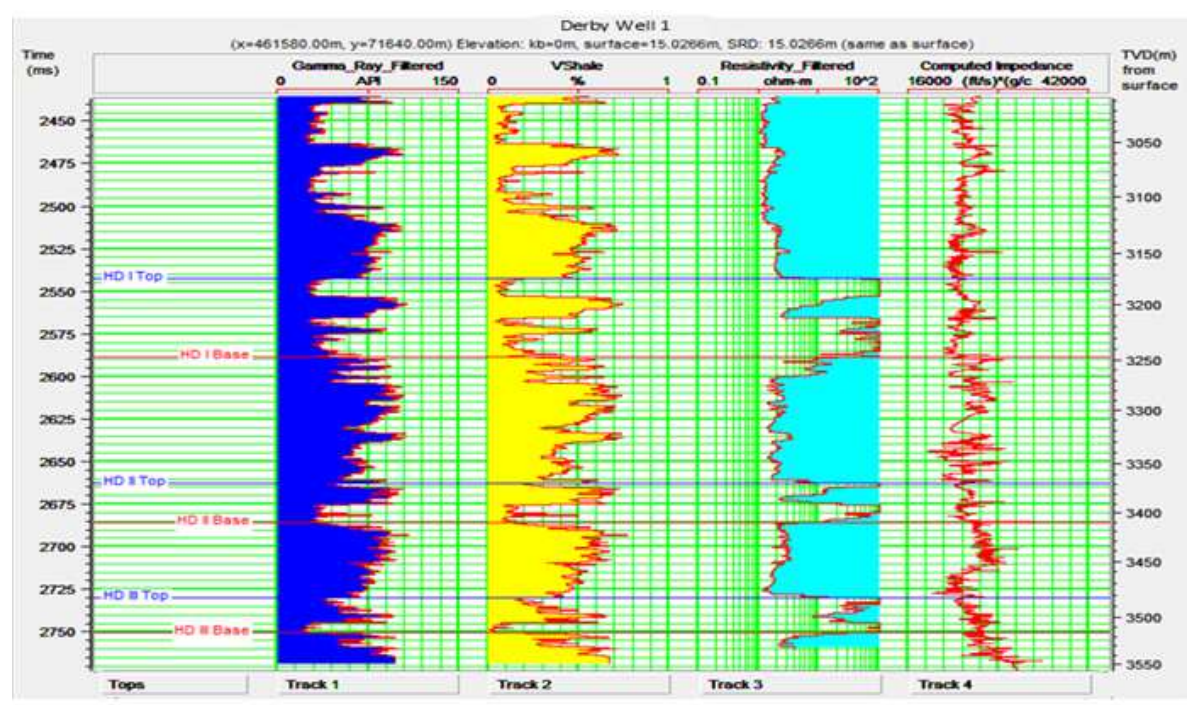

Fig. 4. Derby well 1 showing suite of logs used in identifying prospective tops

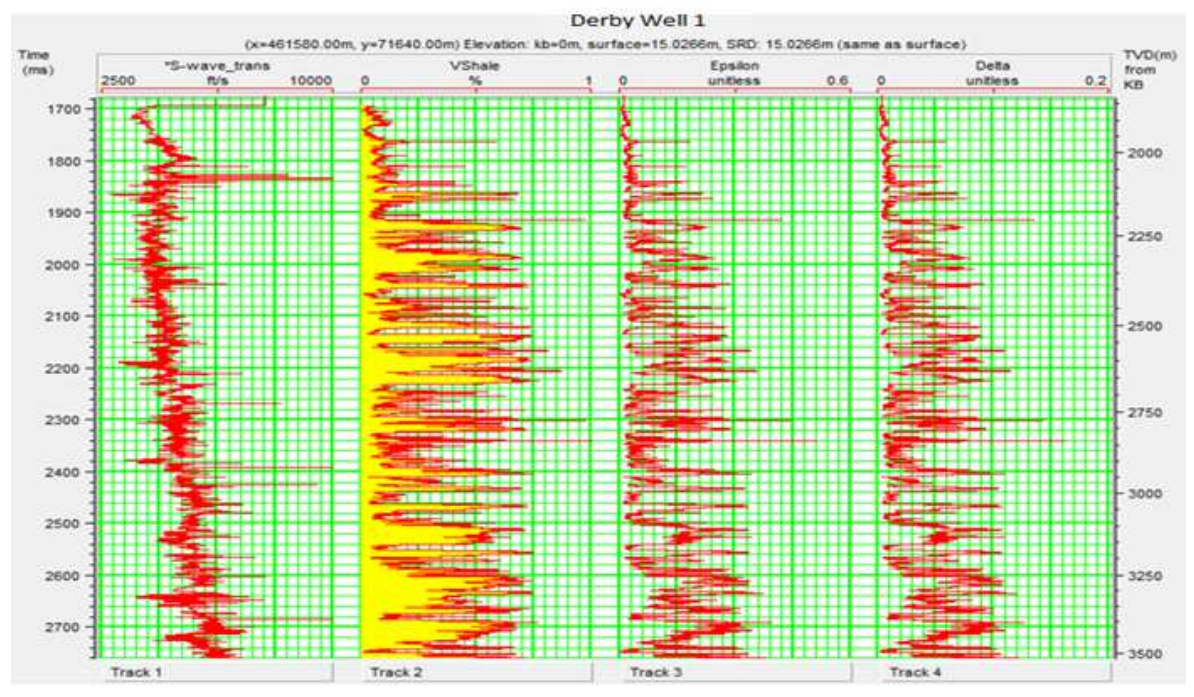

Fig. 5. Computed S-wave, Thomsen epsilon and delta logs for derby well 1

\section{Presentation of Results}

The results of the anisotropic well log, Zoeppritz's plan wave and elastic spherical wave anisotropic AVO synthetic gathers and the real CDP super gather are shown in Fig. 6 Track 1.2 and 3 are the Vshale, epsilon and delta anisotropic logs, while track 4, 5 and 6 are the elastic spherical, Zoeppritz's plane wave and real seismic CDP gathers, respectively.

Results show that Thomson's epsilon $(\varepsilon)$ and delta $(\sigma)$ anisotropic logs are low in gas reservoir sands and high in non-reservoir shale formations in the well. This is an evidence of fact that anisotropy exist and is stronger in shale than gas sands. However, epsilon $(\varepsilon)$ is greater than delta $(\sigma)$ anisotropic log in each case of the reservoir sands and shale in the study area.
Careful inspection of the Zoeppritz's plane wave and elastic spherical wave anisotropic synthetic models over the gas sand tops HDI, HDII and HDIII, respectively, show that reflections are stronger at near offsets and weak at far offsets.

Comparison of the AVO responses from the results of Zoeppritz's plane wave and elastic spherical wave anisotropic synthetic models show opposite AVO effects over the gas sand tops. The plane wave model shows large AVO responses at near offset rapidly decreasing with offset, while the spherical wave model shows moderate AVO responses with less decreased amplitudes with offset. The models generally show AVO effects decreasing with offset. However, this effects are greater for the Zoeppritz's plane wave than the elastic spherical wave synthetic model. 


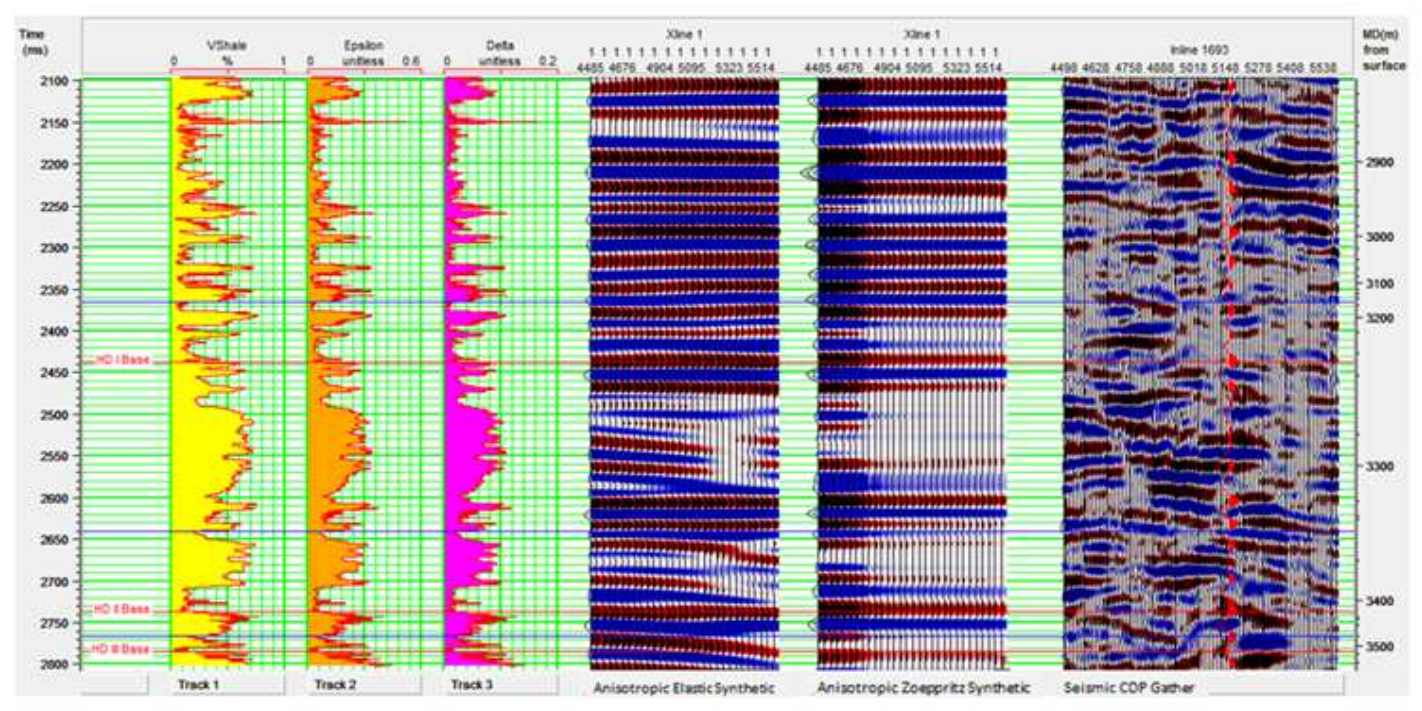

Fig. 6. Comparison of real CDP gather with AVO anisotropic synthetic models

Analysis of results also show that burial depth imparted significantly on the AVO responses of the synthetic models. The effect of burial depth is more pronounced in HDII and HDIII than HDI gas sand tops and greater for Zoeppritz's plane wave than the elastic spherical wave model. Also, in the non-reservoir shale beds, reflection events were better modelled in elastic than plan wave synthetic model. The elastic model shows strong amplitudes and event continuity with nonhyperbolic move out in shale beds compared to the weak amplitudes and discontinuous reflections in the plane wave model especially, with increasing depth of burial.

Comparison of the anisotropic synthetic models with real seismic CDP gathers around Derby well 1 location show strong correlations in amplitudes and continuity of reflections between the CDP super gather and the elastic spherical wave anisotropic synthetic model than the Zoeppritz's plane wave model especially, along the gas sand tops in the gathers.

\section{Discussion of Results}

Anisotropic AVO synthetic modelling was carried out around Derby well 1 location on shale-gas sand horizons and Zoeppritz's plane wave and elastic spherical wave algorithms were used to generate synthetic models, which were compared with the real seismic CDP gathers to deduce the robust anisotropic model for AVO based analysis in Derby field.

The result of study revealed that anisotropy is stronger in shale than gas sands largely due to intrinsic anisotropy and post depositional diagenesis of shale formations (Ogagarue et al., 2010). Also, burial depth imparted significantly on the AVO responses of the synthetic models. This is more pronounced in HDII and HDIII than HDI gas sand tops largely attributed to the increasing thickness of overburden shale layers and compaction with burial depth, which affects the AVO responses of both models. This effect is greater for the Zoeppritz's plane wave than the elastic spherical wave synthetic model.

The result of Zoeppritz's plane wave and elastic spherical wave synthetic models show that reflections are strong at near offsets and weak at far offsets. The HDI, HDII and HDIII gas sand tops have negative reflections (soft kick) which suggests a consolidated shale over a less consolidated gas sand characteristics of a class IV AVO response typical of the Niger delta petroleum system (Castagna and Swan, 1997; Doust and Omatsola, 1990).

Zoeppritz's plane wave and Elastic spherical wave anisotropic synthetic models show opposite AVO effects over the gas sand tops. The plane wave model shows large AVO responses at near offset rapidly decreasing with offset, while the spherical wave model shows moderate AVO responses with less decreased amplitudes with offset. However, at small offset the plane wave model yields best fit to data but at far offset the plane wave model breaks down especially, near the critical angle and the elastic model dominates. This will amount to improved stack response, reflection amplitudes, event continuity and structural definition at larger offsets on the elastic spherical wave anisotropic synthetic and the real seismic CDP gathers than the plane wave anisotropic synthetic model.

These discrepancies are attributed to the impact of Thomsens anisotropic parameters $\varepsilon$ and $\sigma$ of the overburden shale on the shape of the incident wave front and the magnitude of the incident angle. The incident angle is larger for the plane wave than the spherical wave model in anisotropic media (Li, 2003). Consequently, since anisotropy increases with the incident angle (offset) the plane wave model will therefore, exhibit decreased 
AVO effect than the spherical wave model. However, it is important to note that for both the Zoeppritz's and elastic wave models, the reflection coefficient decreases with offset because of anisotropic effects.

Finally, the elastic model compares favourably well with the real CDP super gathers around the reservoir and non-reservoir zones than the plan wave model. This observation is a practical demonstration of the fact that elastic wave modelling is a much better fit to the seismic data than plane wave model at far offsets. Instead of amplitude jump near critical angle predicted by plane wave model, the elastic wave model yields a more gradual amplitude transition at far offset which coincides with the actual super gather.

\section{Conclusion}

The result of the present analysis reveal that seismic anisotropy for AVO based analysis is better modelled with elastic rather than the conventional Zoeppritz's plane wave model and their approximations for transversely isotropic media in Derby field. This is attributed to the breakdown of the Zoeppritz's plane wave model and their linearized approximations at large offsets or near the critical angle. Using elastic synthetic model for anisotropic AVO analysis will not only ensure that the reservoir will be adequately imaged, but misinterpretation of data and misplacement of the well will be avoided.

\section{Acknowledgement}

We express our appreciation to the Hampson-Russell Corporation and AGIP Oil Company, Port Harcourt for their technical support, without which we would not have succeeded.

\section{Author's Contributions}

Chukwuemeka Ngozi Ehirim: Conception, Processed Data and Discussed results.

Nnamdi Ogbonna Chikezie: Reviewed literature, processed data and presented results.

\section{Ethics}

This article is original and contains unpublished material. The corresponding author confirms that all of the other authors have read and approved the manuscript and no ethical issues involved.

\section{Reference}

Avbovbo, A.A., 1978. Tertiary lithostratigraphy of Niger delta: Bulletin of American association of petroleum. Geology, 62: 295-300.

Castagna, J.P., 2001. AVO analysis. CSEG Recorder, 26: $1-10$.
Castagna, J.P and H.W. Swan, 1997. Principle of AVO cross plotting; ARCO exploration and production technology. University of Oklahoma, Norman.

Doust, H. and E. Omatsola, 1990. Niger Delta. In: Divergent-Passive Margin Basins, Edwards, J.D. and P.A. Santogrossi (Eds.), American Association of Petroleum Geologists, Tulsa, ISBN-10: 0891813268, pp: 239-248.

Ejedawe, J.E., 1981. Patterns of incidence of oil reserves in Niger delta basin. Am. Assoc. Petrol. Geol., 65: 1574-1585.

Evamy, B.D., J. Herebourne, P. Kameling, W.A. Knap and F.A. Molley et al., 1978. Hydrocarbon habitat of Tertiary Niger Delta. Am. Assoc. Petrol. Geol. Bull., 62: 1-39.

Li, Y., 2002. Anisotropic well logs and their applications in seismic analysis. Proceedings of the SEG Annual Meeting, Oct. 6-11, Salt Lake City.

Li, Q., 2003. Pitfall in AVO anisotropic modelling: Plane Vs spherical wave. Hampson-Russel (A CGGVeritas Company).

Ogagarue, D.O., J.O. Ebeniro and C.N. Ehirim, 2010. Velocity anisotropy in the Niger Delta Basin: A case study of prestack time imaging with isotropic and anisotropic velocity models. Archives Phys. Res., 1: 50-57.

Ruger, A., 1997. P-wave reflection coefficients for transversely isotropic models with vertical and horizontal axis of symmetry. Geophysics, 62: 713-722. DOI: $10.1190 / 1.1444405$

Rüger, A., 1997. P-wave reflection coefficients for transversely isotropic models with vertical and horizontal axis of symmetry. Geophysics, 62: 713-722. DOI: $10.1190 / 1.1444405$

Rüger, A., 1998. Variation of P-wave reflectivity with offset and azimuth in anisotropic media. Geophysics, 63: 935-947.

Thomsen, L., 1986. Weak elastics anisotropy. Geophysics, 51: 1954-1966.

Thomsen, L., 2002. Understanding Seismic Anisotropy in exploration and exploitation. SEG/EAGE Distinguished Instructor Short Course (DISC) Tulsa, USA.

Tsvankin, T., G. James, G. Vladmir, V. Mirko and T. Leon, 2010. Seismic anisotropy in exploration and reservoir characterization: An over view. Geophysics, 75: 75A15-75A29.

Veeken, P.C.H. and M. Da Silva, 2004. Seismic inversion methods and some of their constraints. First Break, 22: 47-70. DOI: 10.3997/1365-2397.2004011

Williams, M. and E. Jenner, 2002. Interpreting seismic data in the presence of azimuthal anisotropy; or azimuthal anisotropy in the presence of the seismic interpretation. Lead. Edge, 22: 771-774.

Zhijing, W., 2002. Seismic anisotropy in sedimentary rocks, part 2: Laboratory data. Geophysics, 67: 1423-1440. DOI: 10.1190/1.1512743 